\title{
Expression of Sphingosine-1-phosphate (S1P) on the cerebral vasospasm after subarachnoid hemorrhage in rabbits ${ }^{1}$
}

\author{
Hua Tang', Donggang Zhao", Shaojun Chen ${ }^{\mathrm{III}}$, Ming Fang ${ }^{\mathrm{IV}}$, Feifan Wang ${ }^{\mathrm{V}}$, Ying Cui ${ }^{\mathrm{III}}$, Na Tang ${ }^{\mathrm{III}}$, Qianxue Chen ${ }^{\mathrm{VI}}$ \\ DOI: http://dx.doi.org/10.1590/S0102-865020150100000001
}

${ }^{\mathrm{I}} \mathrm{PhD}$, Department of Neurosurgery, Renmin Hospital of Wuhan University, Hubei Province, P.R.C., China. Intellectual, scientific and design of the study; technical procedures; manuscript writing; supervised all phases of the study.

IIPhD, Department of Neurosurgery, Renmin Hospital of The Three Gorges University, Hubei Province, P.R.C., China. Design of the study, technical procedures, manuscript writing, supervised all phases of the study.

IIIPhD, Department of Neurosurgery, Renmin Hospital of The Three Gorges University, Hubei Province, P.R.C., China. Acquisition and interpretation of data, design of the study, technical procedures.

${ }^{\text {IV }} \mathrm{PhD}$, Department of Neurosurgery, Renmin Hospital of The Three Gorges University, Hubei Province, P.R.C. China. Acquisition and interpretation of data, technical procedures, English language.

vPhD, Department of Neurosurgery, Renmin Hospital of The Three Gorges University, Hubei Province, P.R.C., China. Statistical analysis.

${ }^{v} \mathrm{PhD}$, Department of Neurosurgery, Renmin Hospital of The Three Gorges University, Hubei Province, P.R.C. China. Technical procedures, design and supervised all phases of the study.

\section{ABSTRACT}

PURPOSE: To demonstrate the relationship between of sphingosine-1-phosphate (S1P) expression and subarachnoid hemorrhage (SAH).

METHODS: The basilar arteries from a "double-hemorrhage" rabbit model of SAH were used to investigate the relation between S1P expression and SAH. Various symptoms, including blood clots, basilar artery cross-sectional area, and S1P phosphatase expression were measured at day $3,5,7,9$.

RESULTS: The expression of S1P was enhanced in the cerebral vasospasm after subarachnoid hemorrhage in the rabbits. And S1P expression was consistent with the basilar artery cross-sectional area changes at day 3, 5, 7, 9.

CONCLUSION: Sphingosine-1-phosphate expression in the cerebral arterial may be a new indicator in the development of cerebral vasospasm after subarachnoid hemorrhage and provide a new therapeutic method for SAH.

Key words: Vasospasm, Intracranial. Subarachnoid Hemorrhage. Sphingosine. Rabbits. 


\section{Introduction}

Subarachnoid hemorrhage (SAH) is usually defined as a devastating cerebrovascular disease after bleeding into subarachnoid space ${ }^{1}$. Delayed cerebral vasospasm is a common and potentially incapacitating complication of subarachnoid hemorrhage (SAH). It has been demonstrated to be a significant predictor of adverse outcome and the leading potentially treatable cause of mortality and morbidity in patients with SAH. This phenomenon was first documented angiographically by Ecker and Riemenschneider ${ }^{2}$ and was subsequently correlated to the development of focal neurologic deficits by Fisher et al. ${ }^{3}$. Vasospasm after SAH in humans is biphasic, with an acute and a chronic phase. The acute phase typically occurs three to four hours after the hemorrhage and generally resolves rapidly, whereas the chronic phase typically occurs three to 14 days later ${ }^{4}$. It is characterized by sustained narrowing of the arteries, causing a reduction in cerebral blood flow, which can lead to permanent deficits and death in $20 \%$ to $40 \%$ of patients ${ }^{5-6}$. The outcome and prognosis of SAH is poor ${ }^{7}$. In patients developing cerebral vasospasm after $\mathrm{SAH}$, the risk of mortality is increased 1.5-3 fold in the first two weeks ${ }^{8}$. Current management modalities for this condition include hypervolemic-hemodilution-hypertensive (HHH) therapy ${ }^{9}$, interventional neuroradiological procedures like trans-luminal angioplasty, and administration of drugs such as calcium channel antagonists, HMG-CoA reductase inhibitors (or statins) and endothelin-1 antagonists ${ }^{10-11}$. Despite the limited success achieved by these approaches, 26-38\% patients either develop sequelae or die of severe symptomatic vasospasm ${ }^{12-13}$. The success of the current treatment strategies against delayed cerebral vasospasm after SAH remain inconsistent, and seem to have variable effects on the outcome ${ }^{14}$. Despite its clinical significance and the extensive research efforts placed into elucidating its pathogenesis and therapy, vasospasm remains as an incompletely understood and important clinical problem. Therefore, continuous efforts are being made to improve the management of delayed cerebral vasospasm by developing strategies to enhance cerebral blood flow more effectively.

Lipid mediators, such as sphingosine-1-phosphate (S1P) and lysophosphatidic acid (LPA), derived from membrane sphingolipids and glycerophospholipids, are released by activated platelets and affect the maturation and function of vascular constituents, including endothelial and smooth muscle cells ${ }^{15-18}$. They have gained increasing attention since the discovery of high affinity G-protein coupled receptors ${ }^{19-20}$. Sphingosine-1-phosphate (S1P), a potent lipid-mediator produced from the metabolism of sphingosine by sphingosine kinase 1 (SphK1) and SphK2, acts on a family of G protein-coupled receptors (S1P1-5), and transduces intracellular signals involved in numerous physiological and pathological cellular processes ${ }^{21-22}$. S1P receptor expression has been documented in endothelial as well as in vascular smooth muscle cells ${ }^{19,23}$. Bischoff et al. ${ }^{24,25}$ indeed reported that S1P constricted renal and mesenteric microvessels in vitro and reduced renal and mesenteric blood flow in vivo. As yet, however, there is no study to explore the expression and role of S1P expression in the cerebral vasospasm after SAH. However, whether the $\mathrm{S} 1 \mathrm{P}$ is involved in SAH has not been characterized. Therefore, the purpose of this study is to investigate the time course of S1P expression during cerebral vasospasm after SAH and to clarify the possible role for S1P during cerebral vasospasm. Besides, the study is to evaluate the relationship between S1P expression and $\mathrm{SAH}$, providing a new indicator for $\mathrm{SAH}$ after cerebral vasospasm.

\section{Methods}

All experimental protocols involving animals (including all surgical procedures) were approved by the Animal Care and Use Committee of Three Gorges University and conformed to the Guide for the Care and Use of Laboratory Animals published by the National Institutes of Health. Fifty adult New Zealand White rabbits weighing between 2.5 and $2.8 \mathrm{~kg}$ were acclimated in a humidified room and maintained on a standard pellet diet at the Animal Center of Yichang No.1 Hospital for 10 days before the experiment began.

\section{Double-hemorrhage rabbit model}

Experimental SAH was induced as described elsewhere ${ }^{26}$. Briefly, the rabbits were anesthetized via intramuscular injection of a mixture of ketamine $(25 \mathrm{mg} / \mathrm{kg})$ and droperidol $(1.0 \mathrm{mg} / \mathrm{kg})$ on day 0 . With the rabbit breathing spontaneously, a 23-gauge butterfly needle was inserted percutaneously into the cisterna magna. After withdrawal of $1.5 \mathrm{~mL}$ cerebrospinal fluid (CSF), the same amount of non-heparinized fresh autologous auricular arterial blood was slowly injected into the cisterna magna over 1 minute using aseptic technique. Animals were then kept in a $30^{\circ} \mathrm{C}$ head-down position for 30 minutes. Forty-eight hours after the first $\mathrm{SAH}$, a second $\mathrm{SAH}$ was produced in the same manner as the first. In control animals, the same technique was applied, but sterile saline was used in-stead of blood.

\section{Experimental design}

In experiment, 50 rabbits were assigned randomly to five groups: control, SAH day $3, \mathrm{SAH}$ day 5 , SAH day 7 , and $\mathrm{SAH}$ 
day 9 groups. The animals in the SAH day 3, day 5, day 7 , and day 9 groups were subjected to experimental SAH on days 0 and 2 and were killed on days 3, 5, 7, and 9 respectively. The animals in control group were killed on day 3 . The basilar arteries were taken for hematoxylin and eosin (HE) immunohistochemical staining.

\section{Perfusion-fixation}

The rabbits scheduled for death were anesthetized with an intra-peritoneal injection of ketamine $(100 \mathrm{mg} / \mathrm{kg})$ and xylazine $(0.5 \mathrm{mg} / \mathrm{kg})$. Perfusion-fixation was then performed. The thorax was opened with a cannula placed in the left ventricle, the descending thoracic aorta clamped, and the right atrium open. Per-fusion was begun with $250 \mathrm{ml}$ of physiological phosphate buffer solution (PBS, pH 7.4) at $37^{\circ} \mathrm{C}$, followed by $250 \mathrm{ml}$ of $10 \%$ buffered formaldehyde under a perfusion pressure of $120 \mathrm{~cm}$ $\mathrm{H}_{2} \mathrm{O}$. After perfusion-fixation, the whole brain was removed and immersed in the same fixative solution.

\section{Analysis of S1P phosphatase by flow cytometry}

Basilar artery tissues were washed with PBS and detached with protein dissociation buffer, then S1P phosphatases were stained with anti-S1P phosphatase antibodies (R\&D systems, USA), diluted in $\mathrm{PBS} / 2 \mathrm{mM}$ EDTA and $0.5 \%$ fatty acid free BSA (Calbiochem, Germany). Expression of S1P phosphatase conjugated antibodies was analyzed on a FACS Calibur Cytometer (BD, Franklin Lakes, NJ, USA). Then the phosphorylation status analyzed by flow cytometry FACSAria IIu (BD Biosciences, USA).

\section{Measurement of blood vessel cross-sectional area}

The degree of cerebral vasospasm was evaluated by measuring the cross-sectional area of the basilar artery lumen. Formalin-fixed and paraffin-embedded basilar artery sections (4 $\mu \mathrm{m}$ in thickness) were deparaffinized, hydrated, washed and stained with HE. The cross-sectional area and wall thickness of blood vessels were determined by an investigator who was blinded to the experimental group the animal came from. Measurements were performed using the High Definition Medical Image Analysis Program (HMIAP-2000, developed by Tongji Medical University, China).

Cross-sectional areas were calculated by measuring the perimeter of the vessel lumen and then calculating the area of an equivalent circle (area $=\pi r^{2}$, where $r=$ radius) based on the calculated equivalent $r$ value derived from the perimeter measurement $(\mathrm{r}=$ perimeter $/ 2 \pi)$, thus correcting for vessel deformation and off-transverse sections. For each vessel, three sequential sections (midpoints of the proximal, middle and distal segments) were taken, measured and averaged.

\section{Statistical analysis}

All data were presented as mean \pm standard deviation. SPSS 12.0 was used for statistical analysis of the data (SPSS Inc., Chicago, IL, USA). All data were subjected to one-way analysis of variance. Differences between experimental groups were determined by using Fisher's least significant difference post-test. Statistical significance was inferred at $\mathrm{p}<0.05$.

\section{Results}

\section{General observations and pre-test results}

No significant changes in body weight mean arterial blood pressure, temperature, or injected arterial blood gas data were detected in any of the experimental groups. In the pre-test results, there was no significant difference between the control group and controls killed on days 3, 5, 7, 9 regardless of the time of measurement. As shown in Figure 1, the rabbits in day 1 and day 3 groups exhibited blood clots over the basal surface of the brainstem but the blood staining at the base of the brainstem was not observed in the day 5 , day 7 , and day 9 groups.

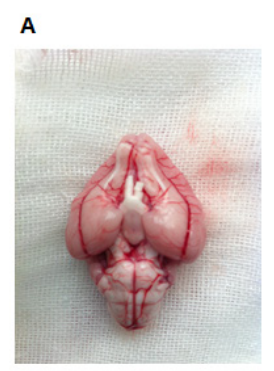

D

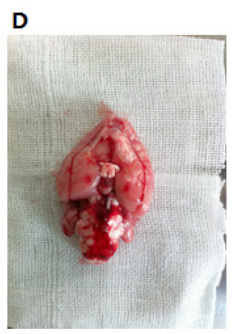

B

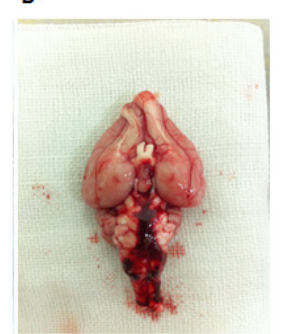

$\mathbf{E}$
C

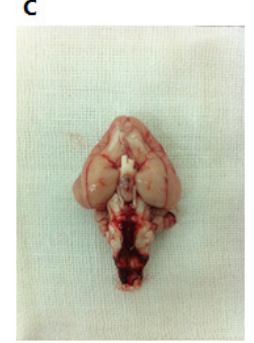

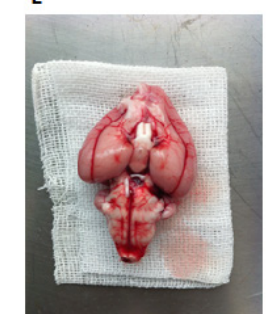

FIGURE 1 - Ventral view of typical brains from Control (A), SAH day 3 (B), SAH day 5 (C), SAH day 7 (D), and SAH day 9 (E) groups. The images in $\mathrm{B}$ and $\mathrm{C}$ showed blood clots at the base of the brainstem. 


\section{The basilar artery cross-sectional area}

As shown in Figure 2, morphometric analysis of the vessels revealed that the mean cross-sectional area of the basilar artery in the day 3 group $\left(288089.6 \pm 100335.0 \mu \mathrm{m}^{2}\right.$, mean $\left.\pm \mathrm{SD}\right)$ showed extremely significant $(\mathrm{p}<0.01)$ compared with the control group $\left(550684.7 .2 \pm 50928.3 \mu \mathrm{m}^{2}\right)$. A moderate reduction was detected in the day 5, 7 group ((331896.6 $\pm 94627.1,437074.2 \pm$ $91768.1 \mu \mathrm{m}^{2}$, respectively) as compared with the normal control value $(\mathrm{p}<0.05, \mathrm{p}<0.01)$. No significant difference was detected between the day 9 group $\left(540441.6 \pm 60967.0 \mu \mathrm{m}^{2}\right)$ and the control group $(\mathrm{p}>0.05)$.

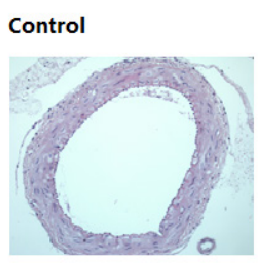

Day 3

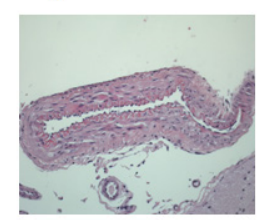

Day 7

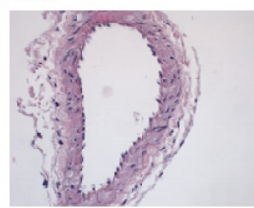

Day 9
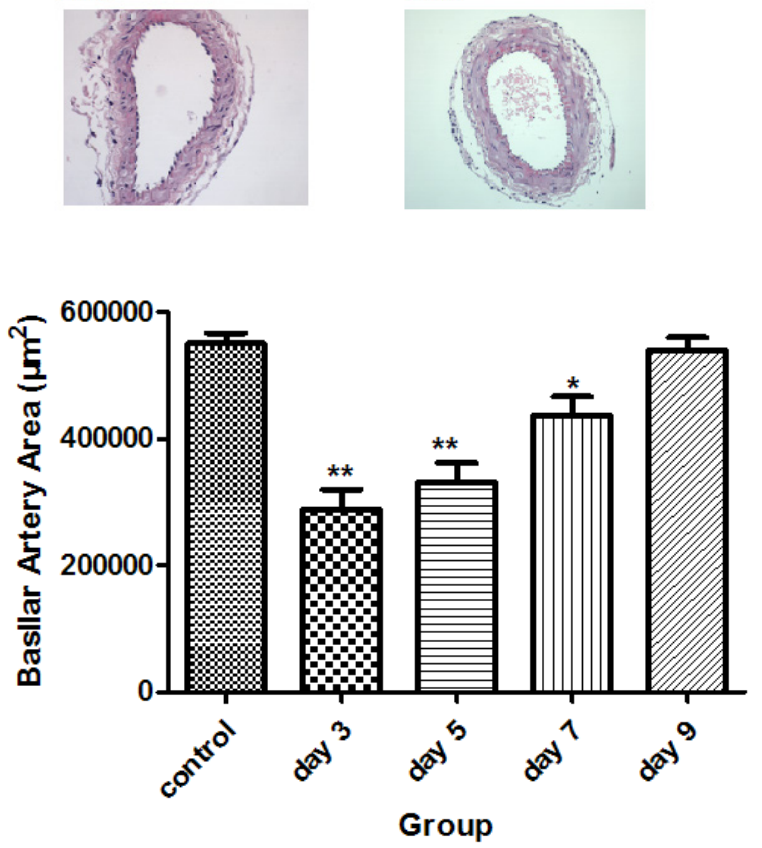

FIGURE 2 - Representative cross-sectional area of basilar arteries of the control rabbits or rabbits subjected to SAH (scale bar, $200 \mu \mathrm{m}$ ). Bars represent the means $\pm \mathrm{SD}\left(\mathrm{n}=10\right.$, each group). ${ }^{* *} \mathrm{p}<0.01 \mathrm{vs}$. control group, ${ }^{*} \mathrm{p}<0.05$ vs. control group.

\section{Expression of S1P phosphatase}

As shown in Figure 3, the expression of S1P phosphatase were increased from day 1 to day 7 , and reached the peak at day 5. And also from the results in Table. 1, the expressions of S1P phosphatase in the experimental rabbits were significantly upregulated compared with the control group, and the expression level reached the peak at day 5 , which is consistent with the result of Flow cytometry (Figure 3 ).

\section{Disscussion}

Delayed or chronic vasospasm is the leading cause of morbidity and mortality after aneurysmal SAH. Although cerebral vasospasm after SAH has been the subject of substantial research interest, the underlying pathogenic mechanisms remain obscure. In the present study, we have demonstrated, for the first time, that the expression of S1P was incresed during cerebral vasospasm after experimental SAH in rabbits. The enhanced expression of S1P could be detected on day 3 , peaked on day 5 , and recovered on day 7. This will lead to the hypothesis that S1P in the cerebral arterial may be a new indicator in the development of cerebral vasospasm after SAH and provide a new therapeutic method for SAH.

In the present study we used a double-hemorrhage rabbit model of cerebral vasospasm to investigate the relationship between S1P expression and SAH. The double-hemorrhage model used in this study had been shown to effectively generate a higher degree of vasospasm with lower mortality, and hence seemed more appropriate than the traditional model of subarachnoid hemorrhage ${ }^{26-28}$. In these $\mathrm{SAH}$ rabbits, the time course of cerebral vasospasm after SAH had a biphasic pattern (i.e. early and delayed vasospasm), similar to that found in humans after SAH. And the models generated by this method follow the same time course of pathological progression as humans, with maximum narrowing of blood vessels at day 7, and therefore were used in this study ${ }^{26}$. The rabbit model and humans also underwent similar morphological changes, and the percutaneous puncture technique was a relatively safe SAH-induction method with a lower mortality rate than dissection surgery ${ }^{29}$.

It is generally accepted that blood vessel walls are sites of essential biological processes, such as blood coagulation and leukocyte extravasation. Endothelial cells, located between circulating blood and vessel wall, play an essential role in the vascular inflammation and immunity ${ }^{30-31}$. What's more, a few studies have demonstrated that vascular smooth muscle displays elements of an innate immune response when stimulated both in vitro and in vivo ${ }^{32-33}$. It is conceivable that vascular smooth muscle is an important site within the vessel for pathogen activation. As mentioned above, Sphingosine-1-phosphate (S1P) and lysophosphatidic acid (LPA) are lysophospholipids that stimulate 

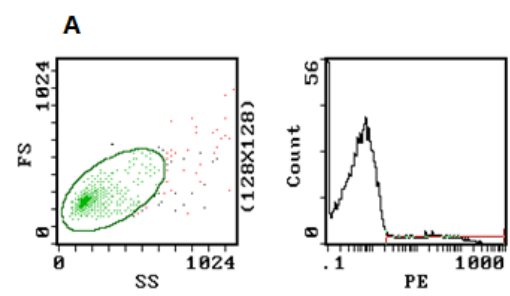

C
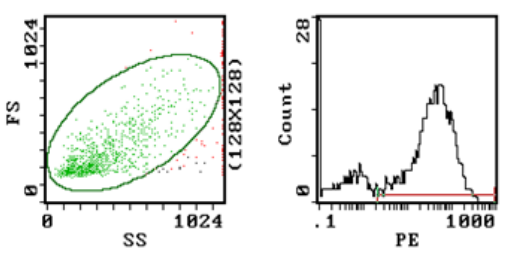

E

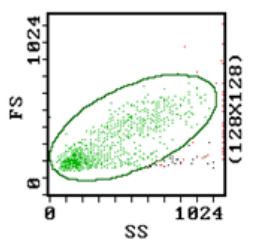

B
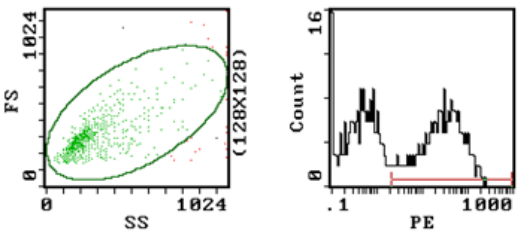

D
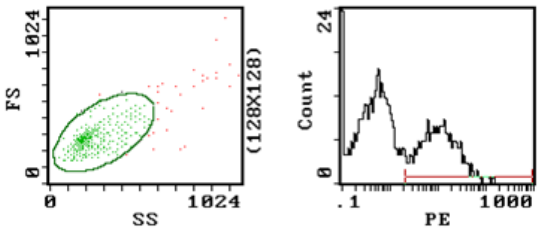

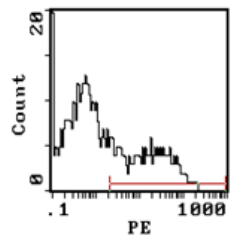

FIGURE 3 - Expression of S1P phosphatase from Control (A), SAH day 3 (B), SAH day 5 (C), SAH day 7 (D), and SAH day 9 (E) groups.

multiple cellular processes, including cell proliferation, stress fiber formation and migration. They activate specific G-proteincoupled receptors $\left(\mathrm{S}_{1} \mathrm{P}_{1-5}, \mathrm{LPA}_{1-4}\right)$ that mediate the biological responses to S1P and LPA. Lysophos-pholipids stimulate the Rho, phospholipase C, Ras/MAP kinase and PI3K pathways, each dependent on specific coupled heterotrimeric G-proteins. The Rho and the PI3K pathways regulate cellular movements that require remodeling of the cytoskeleton, attachment through integrins and detachment as the cell moves forward ${ }^{34}$. S1P might constrict basilar arteries via two independent mechanisms: a high affinity receptor signalling pathway through a Rho protein and a low affinity receptor, signalling through Pertussis sensitive G proteins. While the former pathway would be specific for cerebral blood vessels, the latter would be found in both central and peripheral vessels and might account for the response characterized by Bischoff ${ }^{24}$. In our study, the cross-sectional area of the basilar artery in rabbits subjected to SAH was significantly reduced compared with the normal control group rabbits. And the expression of S1P could be detected on day 3 , peaked on day 5 , and recovered on day 7 in the double-hemorrhage model rabbits. The results showed that the time course of pathological progression of S1P in the rabbit was similar to the humans. Thus, S1P may play a role in inducing constriction of cerebral blood vessels associated with diminishing cerebral blood flow after subarachnoid hemorrhage.

\section{Conclusions}

The expression of sphingosine-1-phosphate was enhanced in the cerebral vasospasm after subarachnoid hemorrhage in the rabbits. And S1P expression was consistent with the basilar artery cross-sectional area changes at day $3,5,7,9$. Thus, the S1P in the cerebral arterial may be a new indicator in the development of cerebral vasospasm after subarachnoid hemorrhage and provide a new therapeutic method for SAH. While the exact role of S1P in the cerebral vasospasm after subarachnoid hemorrhage calls for further study.

\section{References}

1. Suarez JI, Tarr RW, Selman WR. Aneurysmal subarachnoid hemorrhage. N Engl J Med. 2006 Jan;354(4):387-96. PMID: 16436770.

2. Fernando P, Julien L, Pierre A. Pathophysiology, presentation, prognosis, and management of intracranial arterial dolichoectasia. Lancet Neurol. 2015 August;14(8):833-45. PMID: 26194931.

3. Scherle-Matamoros CE, Perez-Nellar J, Fernandez-Cue L. Symptomatic vasospasm: clinical manifestations. Neurocirugia (Astur). 2011 Apr;22(2):116-22. PMID: 21597652.

4. Bedziński P, Imieliński BL, Soniewski P. Vasospasm. Part II - Onset time, localization, etiology. Proposed management algorithm in vasospasm. Neurol Neurochir Pol. 2001 Mar-Apr;35(3):483-92. PMID: 11732270.

5. Haley Jr EC, Kassell NF, Torner JC. A randomized trial of two doses of nicardipine in aneurysmal subarachnoid hemorrhage. A report of the cooperative aneurysm study. J Neurosurg. 1994 May;80(5):788-96. PMID: 8169616. 
6. Navid G, Seyed MRH, Enayatollah AN, Shabnam N. timing of surgery for aneurysmal subarachnoid hemorrhage. Acta Medica Iranica. 2012 Nov;50(5):300-4. PMID: 22837081

7. Nolan CP, Macdonald RL. Can angiographic vasospasm be used as a surrogate marker in evaluating therapeutic interventions for cerebral vasospasm? Neurosurg Focus. 2006 Sep;21(3):E1. PMID: 17029333.

8. Biller J, Godersky JC, Adams Jr HP. The clinical profile, management, and overall outcome of aneurysmal subarachnoid hemorrhage at the neurosurgical unit of a tertiary care center in India. J Neurosci Rural Pract. 2014 Apr;5(2):113-4. PMID: 24966544.

9. Hunt MA, Bhardwaj A. Caveats for triple-H therapy in the management of vasospasm after aneurysmal subarachnoid hemorrhage. Crit Care Med. 2007 Aug;35(8):1985-86. PMID: 17667248.

10. Athar MK, Levine JM. Treatment options for cerebral vasospasm in aneurysmal subarachnoid hemorrhage. Neurotherapeutics. 2012 Jan;9(1):37-43. PMID: 22215324.

11. Siasios I, Kapsalaki EZ, Fountas KN. Cerebral vasospasm pharmacological treatment: an update. Neurol Res Int. 2013 Jan;57(31):1328. PMID: 23431440.

12. Dorsch NW. Cerebral arterial spasm-a clinical review. Br J Neurosurg. 1995 Apr;9(3):403-12. PMID: 7546361.

13. Pandey AS, Elias AE, Chaudhary N, Thompson BG, Gemmete JJ. Endovascular treatment of cerebral vasospasm: vasodilators and angioplasty. Neuroimaging Clin N Am. 2013 Nov;23(4):593-604. PMID: 24156852.

14. Rabinstein AA, Pichemann MA, Friedman JA, Piepgras DG, Nichols DA, McIver JI. Symptomatic vasospasm and outcomes following aneurismal subarachnoid hemorrhage: a comparison between surgical repair and endovascular coil occlusion. J Neurosurg. 2003 Feb;98(2):319-25. PMID: 12593618.

15. Saulnier-Blache JS. Lysophosphatidic acid: a bioactive phospholipid. Med Sci (Paris). 2004 Aug-Sep;20(8-9):799-803. PMID: 15361348.

16. Yatomi Y,Yamamura S, Hisano N, Nakahara K, Igarashi Y, Ozaki Y. Sphingosine 1-phosphate breakdown in platelets. J Biochem. 2004 Oct;136(4):495-502. PMID: 15625319.

17. Hooren KWEM, Spijkers LJA, Breevoort, D, Fernandez-Borja M, Bierings R, Buul, JD, Alewijnse AE, Peters SLM, Voorberg, J. Sphingosine-1-phosphate receptor 3 mediates sphingosine-1phosphate induced release of weibel-palade bodies from endothelial cells. PLoS ONE. 2014 May;9(3):1-7. PMID: 24632890.

18. Liu Y, Wada R, Yamashita T, Mi Y, Deng CX, Hobson JP, Rosenfeldt HM, Nava VE, Chae SS, Lee MJ, Liu CH, Hla T, Spiegel S, Proia RL.Edg-1, the G protein-coupled receptor for sphingosine-1phosphate, is essential for vascular maturation. J Clin Invest. 2000 Oct;106(8):951-61. PMID: 11032855.

19. Hla T, Maciag T. An abundant transcript induced in differentiating human endothelial cells encodes a polypeptide with structural similarities to G-protein-coupled receptors. J Biol Chem. 1990;265:9308-13. PMID: 2160972.

20. An S. Molecular identification and characterization of G proteincoupled receptors for lysophosphatidic acid and sphingosine 1-phosphate. Ann N Y Acad Sci. 2000 Jun;905(16):25-33. PMID: 10818439.

21. Hla T. Signaling and biological actions of sphingosine 1-phosphate. Pharmacol Res. 2003 May;47(5):401-7. PMID: 12676514

22. Hla T. Physiological and pathological actions of sphingosine 1-phosphate. Semin. Cell Dev Biol. 2004 Oct;15(5):513-20. PMID: 15271296.

23. Okazaki H, Ishizaka N, Sakurai T, Kurokawa K, Goto K, Kumada M, Takuwa Y. Molecular cloning of a novel putative G proteincoupled receptor expressed in the cardiovascular system. Biochem Biophys Res Commun. 1993 Feb;190(3):1104-9. PMID: 8382486.

24. Bischoff A, Czyborra P, Fetscher C, Meyer Zu Heringdorf D, JakobsKH, Michel MC. Sphingosine-1-phosphate and sphingosylphosphorylcholine constrict renal and mesenteric microvessels in vitro. Br J Pharmacol. 2000 Aug;130(8):1871-7. PMID: 10952677.

25. Bischoff A, Czyborra P, Meyer Zu Heringdorf D, Jakobs KH, Michel MC. Sphingosine-1-phosphate reduces rat renal and mesenteric blood flow in vivo in a pertussis toxin-sensitive manner. $\mathrm{Br} \mathrm{J}$ Pharmacol. 2000 Aug;130(8):1878-83. PMID: 10952678.

26. Meng LZ, Ji XS, Jia QZ. Comparison between one- and twohemorrhage models of cerebral vasospasm in rabbits. J Neurosci Methods. 2007 Jan;159(2):318-23. PMID: 16942802.

27. Gules I, Satoh M, Clower BR, Nanda A, Zhang JH. Comparison of three rat models of cerebral vasospasm. Am J Physiol Heart Circ Physiol. 2002 Dec;283(6):551-9. PMID: 12427599.

28. Lee JY, Huang DL, Keep R, Sagher O. Characterization of an improved double hemorrhage rat model for the study of delayed cerebral vasospasm. J Neurosci Methods. 2008 May;168(2):358-66. PMID: 18096241.

29. Zhao XD, Zhou YT, Wu Y, Zhuang Z, Huang RQ, Song ZJ, Yin HX. Potential role of Ras in cerebral vasospasm after experimental subarachnoid hemorrhage in rabbits. J Clin Neurosci. 2010 Nov;17(11):1407-11. PMID: 20729088.

30. Luscher TF, Barton M. Biology of the endothelium. Clin Cardiol. 1997 Sep;20(9):3-10. PMID: 9294667.

31. Biedermann BC. Vascular endothelium: checkpoint for inflammation and immunity. News Physiol Sci. 2001 Apr;16(1):84-8. PMID: 11390955.

32. Sasaki T, Kasuya H, Onda H, Sasahara A, Goto S, Hori T, Inoue I. Role of p38 mitogen-activated protein kinase on cerebral vasospasm after subarachnoid hemorrhage. Stroke. 2004 Jun;35(6):1466-70. PMID: 15118180.

33. Jimenez R, Belcher E, Sriskandan S, Lucas R, McMaster S, Vojnovic I, Warner TD, Mitchell JA. Role of Toll-like receptors 2 and 4 in the induction of cyclooxygenase-2 in vascular smooth muscle. Proc Natl Acad Sci USA. 2005 Mar;102(12):4637-42. PMID: 15755814.

34. Anliker B, Chun J. Lysophospholipid G protein-coupled receptors. J Biol Chem. 2004 May;279(20):20555-8. PMID: 15023998.

\section{Correspondence:}

Qianxue Chen

Department of Neurosurgery, Renmin Hospital of Wuhan University Wuhan 430060, Hubei Province, P.R.C.

chenqx666@sohu.com

Received: Jun 16, 2015

Review: Aug 18, 2015

Accepted: Sep 17, 2015

Conflict of interest: none

Financial source: none

${ }^{1}$ Research performed at Department of Neurosurgery, Renmin Hospital of The Three Gorges University, Hubei Province, P.R.C., China. 